\title{
The Coherence of Luck Egalitarianism
}

\author{
Gideon Elford ${ }^{1,2}$
}

Accepted: 14 March 2017 / Published online: 8 April 2017

(C) The Author(s) 2017. This article is published with open access at Springerlink.com

\begin{abstract}
One of the foremost egalitarian theories in recent years, luck egalitarianism, has recently been subjected to the charge that it is in fact incoherent. This charge is brought by David Miller who highlights two dimensions of luck egalitarianism: on the one hand a commitment to the justice of certain inequalities arising from responsible choices; on the other a commitment to injustice of brute inequalities. The putative incoherence emerges in cases where the inequalities that justice requires on the basis of individuals' responsible choices also entail brute luck inequalities for which there are the very same grounds of justice to condemn. Here I argue that the charge of incoherence against luck egalitarianism fails. In service of this I clarify the quite specific sense in which luck egalitarianism requires inequalities and demonstrate the coherence of this with its condemnation of other inequalities.
\end{abstract}

Keywords Luck egalitarianism $\cdot$ Equality $\cdot$ Justice $\cdot$ Fairness $\cdot$ Coherence

Luck Egalitarianism and the variously related family of responsibility-sensitive views of equality of which it is a prominent member are widely held but also extensively contested. As much as there seemed at one time, as Jeremy Waldron (2013: 21) lamented, to be an ever proliferating multitude of variant flavours of the luck egalitarian view, there have been a similarly wide-ranging swathe of criticisms over recent years (Anderson, 1999; Scheffler, 2003; Scheffler, 2005; Wolff, 1998). Amongst that critical collection a novel and potentially powerful objection has recently been raised: that luck egalitarianism, is, contrary to what its advocates have supposed, in fact internally incoherent. Should such a charge be substantiated its significance should not be understated. After all, if it genuinely transpired that the luck egalitarian view, and the variants to which Waldron referred, lack what would seem to be a fundamental prerequisite of any respectable position - that of coherence - it would be a devastating blow to one of the foremost understandings of the value of equality over recent years and, quite conceivably, a decisive reason to reject it.

Gideon Elford

Gideon.elford@new.ox.ac.uk

1 Department of Politics and International Relations, University of Oxford, Oxford, UK

2 New College, Oxford OX1 3BN, UK 
The challenge to the coherence of luck egalitarianism is found in a recent paper from David Miller (2014). Miller highlights two dimensions of the luck egalitarian view: on the one hand luck egalitarians are committed to the view that certain inequalities that arise from responsible choices are required on grounds of justice. On the other hand luck egalitarians are also committed to the view that unchosen inequalities are objectionable, again on grounds of justice. The problem, and putative incoherence, emerges in cases where the inequalities that justice requires on the basis of individuals' responsible choices also entail inequalities for which there are the very same grounds of justice to condemn. That is, there are cases where individuals choose in ways that make them worse off than others such that luck egalitarianism tells us to leave that inequality in place. However if that very same choice results in inequalities between other persons affected by that choice, luck egalitarianism also tells us to eliminate that inequality. On the surface, therefore, it appears that luck egalitarianism issues conflicting mandates - leave the consequences of individuals' choices in place (because they reflect inequalities required by justice) but also eliminate the consequences of individuals' choices (because they reflect inequalities between others condemned by justice). What is still more potentially troubling for luck egalitarianism is that it seems that the cases in which luck egalitarianism issues these conflicting mandates are not rare or idiosyncratic ones but commonplace.

Here I defend the luck egalitarian view against that charge of incoherence and explain how the internal tensions within the luck egalitarian view to which the objection points are, in fact, simply emblematic of the general conflict between liberty and equality and not reflective of an otherwise fatal internal inconsistency. First I detail the putative incoherence that Miller identifies in the luck egalitarian view. I argue that the main case Miller makes in favour of that incoherence fails and does so largely for reasons associated with the construction of a false standard for a successful luck egalitarian rebuttal. Second I consider a stronger case in favour of luck egalitarian incoherence that is present but underexplored in Miller's own account. I suggest that this stronger case depends on emphasising the idea that luck egalitarianism requires inequality. In response to this case I explain that luck egalitarianism requires inequality only in a quite specific sense; a sense that does not provoke incoherence with further inequalities that luck egalitarianism condemns.

\section{The Incoherence of Luck Egalitarianism?}

In the course of explaining why the charge to luck egalitarianism of incoherence falls short, I don't intend to offer an exhaustive and detailed specification of the luck egalitarian view, nor will I explore the variants of the luck egalitarian view (hereafter 'responsibility-sensitive egalitarian' views) and the respects in which they differ from the ancestor view. Instead I will examine the details of the luck egalitarian view and any variance among responsibilitysensitive forms of egalitarianism at relevant junctures where it becomes material to the discussion. For now it will suffice to recapitulate the distinction at the heart of the luck egalitarian view between consequences that qualify as option luck - the consequences persons encounter as a result of, in Dworkin's (1981: 281) words, “deliberate and calculated gambles", broadly construed, that they have taken - and consequences that qualify as brute luck - all consequences for persons that fail to count as gambles in that sense. On the luck egalitarian view inequalities in the latter are (with caveats to be explained) unfair and for that reason objectionable at the bar of justice whereas inequalities in the former are not unfair, so not 
objectionable on those justice grounds. Importantly, inequalities licensed by option luck are not only permitted in the sense that they are not unfair but that they are required in the sense that their elimination is unfair.

Broadly put, Miller's claim is that this conjunctive opposition to brute luck inequalities alongside a commitment to allowing option luck inequalities embodies an internal incoherence. This is so because the choices people make can be option luck for them but brute luck for others and if luck egalitarianism tells us to allow option luck inequality but eliminate brute luck inequality then it offers inconsistent mandates with respect to whether should allow or restrict the consequences of individuals' choices. Crucially, then, the putative conflict arises in virtue of the fact that our choices affect others. In cases of purely self-affecting choices there is no incoherence. Miller (2014: 137) offers the self-affecting example of two persons waiting for peaches to ripen. He writes, "imagine that you and I each begin with a bowl of unripe peaches, but whereas you wait carefully until the fruit has reached its ripest condition, and then begin to eat, I am either too hasty or too dilatory and therefore get less enjoyment from my fruit." Whilst I am worse off than you this is a paradigm case in which the inequality between us is the fair result of our respective responsible choices. However very few of our choices have only a self-affecting dimension but rather also affect other persons and the levels of advantage they enjoy.

Cases of gift-giving offer perhaps the most straightforward illustration of the issue. If $\mathrm{A}$ gives to B this enhances B's level of advantage. Now, in a two-person case it would seem that there is no unfairness. While A is worse off than B, it's as a result of a choice they made themselves. Where there are third parties, however, this is not the case. Consider $\mathrm{C}$, who does not receive a gift from $\mathrm{A}$. The gift $\mathrm{B}$ receives is a brute luck advantage that $\mathrm{C}$ doesn't receive. Through no fault or choice of their own $\mathrm{C}$ is worse off than B as a result of A's gift-giving. As such, the inequality between $\mathrm{B}$ and $\mathrm{C}$ is objectionable at the bar of luck egalitarian justice. ${ }^{1}$ However, Miller contends, this is incoherent with the luck egalitarian support for inequalities that are the result of responsible choice; for luck egalitarianism judges the inequality between $\mathrm{A}$ and $\mathrm{B}$ a just one. The luck egalitarian is at once committed to supporting inequality generated by A's choice and simultaneously condemning it. As Miller (2014: 140) puts it, "[T]he two halves of the principle appear to be at war with one another." The majority of the remaining case Miller makes in favour of this incoherence is devoted to considering and rebutting possible avenues of response for luck egalitarians.

My defence of the coherence of luck egalitarianism runs as follows. I begin by explaining how one way of reading Miller's argument is as merely drawing attention to the widely recognised conflict between liberty and equality. Whilst I will suggest that much of the case that Miller makes for incoherence endemic to luck egalitarianism trades on that familiar tension, there is in fact a deeper tension that Miller's argument alerts us to. I then go on to establish how even this deeper tension does not represent an incoherence in the luck egalitarian view.

The charge of incoherence purports to be something more than the claim that equality is in tension with considerations of individuals' liberty. Rather it is that in seeking to accommodate choice and responsibility, luck egalitarianism has incorporated considerations of liberty only at the cost of internal coherence. It is because those values are bound to conflict with one another that any such attempt at harmonisation is bound to fail. This thought should be met with resistance. The claim from the luck egalitarian camp was never that all considerations of

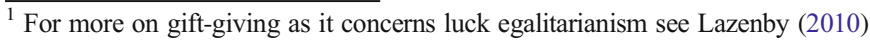


individual liberty could be rendered consistent with an appropriately responsibility-sensitive understanding of the value of equality but that some could. The luck egalitarian view is entirely consistent with the idea that persons' exercise of their liberty may have equality-upsetting implications, say, when some benefit from gifts to a greater extent than others. Miller (2014: $138,141)$ observes how luck egalitarians tend to explain the responsibility-sensitivity of their view via examples of choices persons make which affect only themselves. Luck egalitarians might argue that there is good reason for this precisely because it is the self-affecting dimensions of choices that the view internalises. That is, the claim was only ever that persons had no egalitarian complaint when their choices rendered themselves worse off, not that persons have no egalitarian complaint against being made worse off in virtue of others choices. As I intimate above, the idea that people make choices which have a tendency to upset egalitarian patterns of distribution is hardly a novel one, and not, I will argue, one that embodies a particular incoherence within the luck egalitarian view itself. ${ }^{2}$

All of that said, I want to consider and respond to a stronger case for the incoherence of luck egalitarianism undergirding Miller's concerns. The case in question involves emphasising the idea that luck egalitarianism requires certain inequalities on grounds of fairness. To uncover and reply to this possible line of argument is an unavoidably technical endeavour, however, as I hope will become clear, carefully trawling through the detail is a necessary means of executing a rescue of luck egalitarianism from the kind of incoherence with which it is threatened.

\section{The Coherence of Luck Egalitarianism}

Miller uses two kinds of cases of other-affecting choice to illustrate the putative incoherence in Luck Egalitarianism. The gift-giving case in the above is one kind of case - where third parties are rendered comparatively worse off than others who receive gifts that they do not. If $\mathrm{B}$ receives a gift from $\mathrm{A}$ that $\mathrm{C}$ does not, luck egalitarianism condemns the unequal distribution between $\mathrm{B}$ and $\mathrm{C}$ as unfair. The second kind of case does not draw third parties into focus but emphasises a choosing party affecting a second party's level of advantage. In both kinds of case, Miller argues, Luck Egalitarianism issues conflicting mandates, on the one hand to allow the inequality in distribution because it was a result of some individual's choice, on the other hand to eliminate the inequality in distribution because it creates brute luck inequality. In fact these two kinds of cases are really importantly different from one another and, perhaps

\footnotetext{
${ }^{2}$ It is in this context that Miller emphasises that any claim luck egalitarians can lay to successfully have incorporated of the ideas of choice and responsibility into an ideal of equality depends on their being incorporated in a substantial enough way so as to mean that equality is consistent with individuals enjoying the scope for responsibility luck egalitarianism appeared to promise. He considers a series of hypothetical luck egalitarian responses to the charge of incoherence the majority of which, Miller (2014: 140 - 146) argues, involve measures which effectively deprive individuals of meaningful scope of choices (and do so because of the general propensity of choice to upset egalitarian fairness). The problem with Miller adopting this strategy is that this isn't really a case in favour of incoherence. At most it establishes that the avenues of coherence for luck egalitarianism are less responsibility-sensitive than they appear at first glance. None of this is to say that Miller's work is not of some service here. By pressing this critique he clarifies the specific way in which the idea of choice and responsibility has been incorporated into the luck egalitarian view and moderates any overinflated claims to reconciliation between liberty and equality. The way Miller's argument is framed, however, wrongly supposes that that the purpose of luck egalitarianism was to convert anti-egalitarian critics by confronting them on their own terms and, as such, it sets a false standard for success that luck egalitarianism never purported to attain.
} 
contrary to appearances, the latter kind of case does not pose obvious difficulty for a suitably characterised version of luck egalitarianism.

Cases of the second kind include where "I use my resources in a way that enhances or diminishes the value of yours," or where "I enter an auction and bid against you, forcing the price of the good that you want to buy to go higher than it otherwise would," or where "I choose to put my car up for sale, and the buyer who would have otherwise have bought yours chooses mine, with the consequence that you are only able to sell yours for a lesser amount." (Miller, 2014: 139) These are all cases where one person's choice, by affecting another, creates brute luck inequality in the form of disadvantages for that other person. Notwithstanding appearances to the contrary, these are not inequalities that a plausible version of luck egalitarianism has reason to object to. ${ }^{3}$

This is because, as I (2013) have previously argued, contrary to popular ways of articulating the view, luck egalitarianism should not be understood in terms of requiring brute luck equality. To briefly explain, consider someone endowing another with positive brute luck. If A gives to B this results in B enjoying a positive brute luck transfer. ${ }^{4}$ In this way B enjoys a brute luck transfer that A does not, resulting in brute luck inequality between the two. Now, it is tempting to see this not as a matter of brute luck inequality but merely an issue of option luck for A. This isn't quite right, however. To see this, assume an initially equal distribution of the following: $A=10 ; B=10$. Let's say A transfers 10 to $B$. A's marginal deficit of -10 is option luck; a loss that is the direct consequence of a choice they make. ${ }^{5}$ But B's +10 gain isn't option luck for A. It isn't option luck because option luck is specified in terms of self-affecting gains/losses (and B's gain isn't self-affecting for A). From B's perspective the receipt of +10 is good brute luck. As such B receives a +10 brute luck gain that A does not (because B does not give A a gift). Despite the existence of brute luck inequality, this hardly seems to be an inequality in distribution to which luck egalitarians have a reason to object. As I (2013: 140) have argued, the luck egalitarian view is better understood in terms of each individual having equal opportunity to avoid being worse off than any other, rather than in terms of brute luck equality. A has an equal opportunity to avoid being worse off than B should he/she refrain from transferring 10 to $\mathrm{B}$. The fact that transferring a gift creates a brute luck inequality in this two-person case, does not generate an inequality of luck egalitarian concern. This should be just as clear where persons' choices negatively affect others' brute luck. Imagine a case where both Jerry and Jimmy have equal claims to a piece of land which will be divided equally between all those who exercise their claim. Let's say that Jimmy enters a claim for a share of land. Should Jerry opt to also claim the land this would represent bad brute luck for Jimmy as it would mean a lower share. This is in just the same way Jimmy's claim is bad brute luck for Jerry. Whether or not Jerry opts to enter a claim it's hard to see the luck egalitarian objection to any inequality in distribution given that any inequality in brute luck is one that Jerry has an equal opportunity to avoid. If this is true, then a whole category of other-affecting choices which Miller classifies as problematic for luck egalitarianism are, in fact, not so. ${ }^{6}$ Cases where persons are better or worse off than others in brute luck terms are ones which luck

\footnotetext{
${ }^{3}$ Unless, of course, the inequalities relate to third parties, and then they are examples of the first case.

${ }^{4}$ If one is tempted to think that the receipt of the gift is option luck for B because they choose to accept it, then consider that the mere offer of a gift represents a brute luck advantage.

5 Strictly speaking, then, it's not option luck, at least as Dworkin defines it, because it's a loss that does not depend on the fallout of risk. This qualification does not affect the substance of the argument.

${ }^{6}$ What range and number of acts typically fall into this category is, of course, a further question.
} 
egalitarianism has a reason to object to only if those persons lacked an equal opportunity to be as well off in brute luck terms than others.

In the above I suggested a possible straightforward answer to Miller's charge of incoherence would be for the luck egalitarian to simply agree that inequality generating consequences of other-affecting choices are unfair and call for egalitarian redistribution. Luck egalitarianism is thereby rescued from incoherence, even if it is at the expense of conceding that the view is less sensitive to responsibility than surface impressions suggest. It might be said, however, that this response ignores the sense in which luck egalitarianism requires inequality generated by responsible choices which was the very dimension of the luck egalitarian view that created the incoherence in the first place. Miller (2014: 136 - 137) does at one point emphasise that luck egalitarianism requires rather than merely permits inequality and that for authors like Cohen there can be unjust equality. Surprisingly he does not then press this as a crucial part of the case for incoherence.

Uncovering the particular sense in which luck egalitarianism might be said to require inequality is an important part of dissipating the putative incoherence to which Miller points. In what sense, then, does luck egalitarianism require inequality? To require inequality in the relevant sense is to say that the inequality in question is not merely permitted (because not unfair) but that its elimination would be unfair. ${ }^{7}$ It seems clear that standard views of luck egalitarianism do require some inequality in this sense. ${ }^{8}$ The question is whether that requirement provokes an incoherence with other aspects of the luck egalitarian view. I argue not.

To explain why let's first take the two-person gift-giving case, again assuming an initially equal distribution of: $\mathrm{A}=10 ; \mathrm{B}=10$. If $\mathrm{A}$ gives 10 to $\mathrm{B}$, in what sense is inequality required between them? Crucially, I suggest, luck egalitarianism requires inequality only in the sense that the marginal -10 loss for A resulting from his/her choice is classified as option luck and in that way taken off his/her brute luck ledger, so to speak. This has the implication that any brute transfer to A eliminating that inequality involves an unfair distribution of brute luck - it would involve A receiving a +20 brute luck gain that B does not. ${ }^{9}$ Now, of course, I've already suggested that luck egalitarianism does not require brute luck equality. However this brute luck inequality is different from the brute luck gain that B receives as a result of A's gift. In the gift case A is comparatively worse off in brute luck terms as a result of his/her own choices (and hence something she had an opportunity to avoid). In contrast, the inequality in brute luck manifested by the +20 inequality eliminating transfer is independent of the choices of $\mathrm{B}$ who is worse off in brute luck terms. For reasons that will become still clearer in the following, then, luck egalitarianism requires an inequality of -10 between $\mathrm{A}$ and $\mathrm{B}$ in virtue of the fact that any distributive move that eliminates this inequality involves an unfair brute luck advantage for $\mathrm{A}$. To repeat, the lesson here is that insofar as luck egalitarianism maintains that A's - 10 be taken off the brute luck ledger, it requires that the self-affecting consequences of individuals' choices do not affect their brute luck.

It's far from clear, however, that luck egalitarianism requires inequality in the sense that it requires both the self-affecting and the other-affecting consequences of a choice to be taken off the brute luck ledger. Here it seems like the sensible luck egalitarian thing to say is that the inequality is permitted but not required. After all, the other-affecting part of the inequality - the

\footnotetext{
${ }^{7}$ As Cohen (2011b: 121, his emphasis) puts it, the egalitarian of this sort is "against equalities in the presence of appropriately differential responsibility."

${ }^{8}$ For an alternative (what I take to be non-standard) view of luck egalitarianism in this regard see Segall 2015.

${ }^{9}$ After the gift of 10 from $\mathrm{A}$ to $\mathrm{B}$, the distribution stands as follows: $\mathrm{A}=0 ; \mathrm{B}=+20$. To render them equal without taking from $\mathrm{B}$ involves $\mathrm{a}+20$ transfer to $\mathrm{A}$.
} 
+10 B receives in our example - is brute luck for B. Whilst, as I've argued, luck egalitarianism doesn't judge that brute luck inequality an unfair one (as A had equal opportunity to avoid it) it's also not clear that it judges it required by fairness.

For instance, intuitions in favour of requiring inequality on grounds of fairness are ordinarily stoked via appeals to cases of people depleting their existing stock of brute luck advantage (by wasting it for instance) or by profiting by enhancing its value (by investing wisely perhaps). ${ }^{10}$ Commonly, then, the question is pressed why others should be asked to bear the costs/allowed to reap the rewards, either by redistribution or by affecting future distributive entitlements, when those disadvantages/advantages are things for which the persons are responsible? ${ }^{11}$ As the reader will no doubt notice, the focus here is on the self-affecting costs and benefits of the responsible choices and the fact that fairness requires a distributive insensitivity to them. To distil this thought, imagine a case where A benefits B in a way that involves no sacrifice on A's behalf, for instance by costlessly creating a +10 gain for B. My contention is that the brute luck inequality that now obtains between them is not one luck egalitarianism condemns as unfair ${ }^{12}$ and, crucially, it is not one the elimination of which the luck egalitarian would judge as unfair. ${ }^{13}$ If we transfer +10 to $\mathrm{A}$ in order to eliminate the inequality, for instance, the fairness grounds on which B might object to that transfer are unclear. It could be said that this rectifying transfer is a brute gain that B doesn't receive, but, of course, B receives a +10 brute gain that A doesn't via the original costless benefit A creates for B. ${ }^{14}$ Perhaps B might claim that the +10 he/she originally receives from A should be taken off the brute luck ledger. In that case, any +10 transfer to A constitutes a brute luck inequality to which luck egalitarianism should object on grounds of fairness. But, of course, B cannot invoke the idea that the other-affecting transfer from A should be taken off the brute luck ledger as grounds for the unfairness of eliminating the inequality it creates; this is precisely what is in question.

Of course, one might just stubbornly claim that luck egalitarianism does require inequality in the sense that covers the consequences of other-affecting choices. If this is a claim about what luck egalitarian theorists have typically maintained then firstly it's not clear that it's accurate but secondly, and more importantly, it shows only that there is a possible way of understanding luck egalitarianism that is liable to the charge of incoherence that Miller levels. One might just offer a 'revised' form of luck egalitarianism along the lines I have suggested that avoids it. In any case, in order to sustain the claim to incoherence one must therefore show either that this 'revised' form itself embodies an incoherence of one form or another or that it entails counterintuitive consequences, depriving the view of any plausibility. In which case luck egalitarianism would escape incoherence only at the expense of failing an independent

\footnotetext{
${ }^{10}$ The ant and the grasshopper being a paradigm case.

11 Again, as Cohen (2011: 121) puts it, "Why should one person pay for another's truly optional choices?"

${ }^{12}$ Even if one thinks that A has some kind of fairness claim on B to costlessly create a similar reward in return, I suggest this would be on the grounds of fairness as reciprocity, rather than a luck egalitarian principle of fairness specifically.

${ }^{13}$ To put it more succinctly, the inequality is, on grounds of fairness, permitted but not required.

${ }^{14}$ Some might find it clearer to think about the issue in terms of the fairness claims A and B respectively have. Does B really have a fairness claim against A receiving this +10 inequality eliminating transfer when she is already the beneficiary of a +10 brute luck gain from A? If not, this supports the idea that the inequality is not required. Does A have a fairness claim to receive $\mathrm{a}+10$ inequality eliminating transfer when it was her own choices that rendered her worse off than B in brute luck terms? If not, this supports the idea that the inequality is permitted.
} 
test of plausibility. Again, though, it's far from clear that it's particularly compelling to claim that other-affecting generated inequalities are required by fairness.

To briefly take stock, the clarification I have offered successfully rescues luck egalitarianism in the following way. The putative incoherence arises because luck egalitarianism requires inequalities that it simultaneously condemns. I have argued that inequalities that luck egalitarianism condemns relate to the consequences of other-affecting choices because they create brute luck inequalities which are in some cases (that I will come to) unfair. However, because luck egalitarianism only requires inequalities constituted by the self-affecting consequences of individuals' own choices, the theory is not saddled with the incoherence that would arise from condemning and requiring the very same inequalities.

To further clarify the preceding defence, let me briefly apply it to third party cases. As I argue in the above, where A transfers 10 to $\mathrm{B}$, this creates an inequality of 20 that is permitted but not required in its entirety. Rather, I have suggested that only an inequality of 10 is required; constituted, as it is, by the negative self-affecting consequences of A's transfer. Now consider the introduction of a third person, C. While in the two person case there is no unfair inequality, in the three person case A's transfer creates an unfair inequality between $\mathrm{B}$ and $\mathrm{C}$. When the distribution is: $\mathrm{A}=0 ; \mathrm{B}=20 ; \mathrm{C}=10, \mathrm{C}$ is comparatively worse off in brute luck terms than B without having an equal opportunity to avoid being so. As such, luck egalitarianism requires the elimination of that unfair inequality between B and C. Now, here is why the above clarification as to which inequalities luck egalitarianism requires is important. If it were true that luck egalitarianism requires the entirety of the inequality between $\mathrm{A}$ and $\mathrm{B}$ to remain in place and luck egalitarianism requires the elimination of the inequality between $\mathrm{B}$ and $\mathrm{C}$, then, as I will further explain, it issues inconsistent mandates. It should be clear at this stage, though, that it does not.

As explained above, there is nothing incoherent or profoundly at odds with the basis for luck egalitarianism to simply say that the a wholly fair distribution would be one in which the other-affecting consequences of A's choice $(+10$ for B) are eliminated; thus preserving equality between $\mathrm{B}$ and $\mathrm{C}$ and preserving the element of required inequality that obtains in virtue of the self-affecting consequences of A's choice (who goes to 0). Such a proposed strategy admittedly involves levelling down and for that reason might be objectionable, but that doesn't amount to incoherence. In any case, there are alternative, non-levelling down, strategies for eliminating the unfair inequality consequential on A's gift. We could redistribute from $\mathrm{B}$ to $\mathrm{C}$ or provide a compensating benefit to $\mathrm{C}$ to offset the unfairness. Both such strategies have some surprising implications, however. Given the argument above, it might seem that redistributing from $\mathrm{B}$ to $\mathrm{C}$ is wholly fair. This leaves $\mathrm{A}$ with $0, \mathrm{~B}$ with 15 and $\mathrm{C}$ with 15. However, compare the position of $A$ and $C$. $C$ is now better off than $A$, over and above the deficit that A faces as a consequence of his/her option luck (remember only -10 of A's deficit, the value of the gift to $\mathrm{B}$, is self-affecting). Why is this unfair, one might ask, particularly given that it's also true of B? Well, the difference is that B's being better off than A to this extent is, we've been supposing, a reasonably anticipated consequence of A's choice. A has no grounds for complaint for being worse off than B to this extent because he/she could have foreseen and avoided being so. So because the brute luck inequality between A and B is reasonably avoidable, it's permitted (but, as per the above argument, not, in its entirety, required) on grounds of fairness. The same isn't necessarily true of the inequality between A and C. Whilst C's +5 gain (from B) in this imagined distribution is a consequence of A's choice in one way as a redistributive measure to correct unfairness A created - it wasn't necessarily a reasonably anticipated consequence of that choice. If it wasn't a reasonably anticipated consequence of 
A's choice then it seems to be a brute luck inequality that A lacked the opportunity to avoid and so should, for the luck egalitarian, count as unfair. ${ }^{15}$

What measures, consistent with luck egalitarianism, are available to remedy this instance of unfairness? I suggest that luck egalitarian fairness is preserved if and only if the redistributive gain that $\mathrm{C}$ receives is equal to $\mathrm{i}$. the final brute luck gain $\mathrm{B}$ receives as a consequence of A's gift ii. any brute gain for A. ${ }^{16}$ Does this contravene the luck egalitarian required inequality constituted by the self-affecting consequences of A's choice? In fact it does not. Luck egalitarianism does not require $\mathrm{A}$ to be non-comparatively worse off to the tune of the marginal - 10 in virtue of giving 10 to $\mathrm{B}$. In the two person case involving only A and B, for instance, there would be no luck egalitarian unfairness in giving each an equal brute luck boost of +10 to take A to 10 and B to 30 (10 originally, +10 gift from A, +10 further brute transfer). Furthermore, under the above conditions, the brute gain for A will never be greater than the brute gain for B (because A's gain must be equal to C's, which is only fair if equal to $B$ 's gain). Because the brute gain to $A$ as a result of this redistribution is never greater than the brute gain to B, any inequality constituted by the self-affecting consequences of A's choice remains in place, thus leaving the required inequality unaffected. To demonstrate, consider the case where we redistribute from $\mathrm{B}$ to $\mathrm{C}$ in order to eliminate unfair inequality between them. This leaves us with a preliminary distribution of $\mathrm{A}=0, \mathrm{~B}=15, \mathrm{C}=15$. I have argued that this is unfair because $\mathrm{C}$ gains +5 brute luck (through the redistributive transfer) that $\mathrm{A}$ does not. It is unfair (on A) because, unlike the +10 brute luck B receives, the brute luck gain to C isn't a reasonably anticipated consequence of A's choice. A brute transfer of +5 to $\mathrm{A}$ (giving us $\mathrm{A}=5$, $\mathrm{B}=15, \mathrm{C}=15$ ) eliminates that unfair inequality between $\mathrm{A}$ and $\mathrm{C}$. $\mathrm{A}$ is still -10 worse off than $\mathrm{B}$ but this is to the tune of the self-affecting consequences of his/her choices. Similarly, although the inequality between $\mathrm{A}$ and $\mathrm{B}$ is less than it would have been prior to these corrective redistributions, the inequality constituted by the self-affecting consequences of A's gift remains in place.

For these reasons the coherence objection to the luck egalitarian view fails. Even if the above defence is viewed as in some measure a revision to archetypal luck egalitarian views this should not be worrisome. It does not involve the sacrifice of anything crucial to luck egalitarianism and, what's more, coheres with the variety of intuitive cases typically marshalled in favour of that view. Now, there might be a worry that because of the nature of the analysis of the above that, if it does amount to a vindication of luck egalitarianism against the coherence charge, it is a vindication on somewhat of a technicality. Though luck egalitarianism can be made formally consistent, perhaps there is still an incoherence of sorts in the sense that the demands of liberty and equality that luck egalitarianism purports to internalise are basically and characteristically in tension with one another, even if we can find possible ways to balance the books. I believe this would be a misconstrual. The chief reason why luck egalitarianism is not incoherent is that it doesn't require the full extent of inequalities resulting from individuals' choices, only the part of the inequality consisting in the consequences of individuals' choices on themselves. As such the luck egalitarian view makes sense of the idea that many of the inequalities generated through effects on others, such instances of differential gift-giving, are unfair (those who don't receive gifts are unfairly worse off than those who do)

\footnotetext{
${ }^{15}$ If, for instance, I plant a fruit bearing tree in my garden and the (reasonably) unanticipated result is seeds drifting into yours, supplying you with a bounty of new fruit bearing trees, there is a luck egalitarian fairness case for redistributing your good fruit-fortune.

${ }^{16}$ Of course, if $\mathrm{C}$ receives any further brute luck over and above this, luck egalitarianism holds that the marginal additional amount should be equal for $\mathrm{A}, \mathrm{B}$ and $\mathrm{C}$.
} 
but does so in a way that is consistent with saying that it's not unfair if the gift-giver themselves is worse off to the tune of whatever they have given up. Of course the unfairness luck egalitarian locates in the differential gifts to others does in some sense run up against the liberty of persons' to give such gifts. ${ }^{17}$ To that extent it's absolutely true that anyone looking to luck egalitarianism for a resolution to the long-standing trade-off between liberty and equality will be disappointed. I would suggest, though, that luck egalitarianism never purported to hold that promise and that it offers at most a moderation of the conflict between those two values. We should conclude, therefore, that whatever reasons there are to reject a luck egalitarian view, the kind of incoherence for which Miller argues is not among them. ${ }^{18}$

Acknowledgements I'd like to thank the two anonymous reviewers of this paper for their most helpful comments.

Open Access This article is distributed under the terms of the Creative Commons Attribution 4.0 International License (http://creativecommons.org/licenses/by/4.0/), which permits unrestricted use, distribution, and reproduction in any medium, provided you give appropriate credit to the original author(s) and the source, provide a link to the Creative Commons license, and indicate if changes were made.

\section{References}

Anderson E (1999) What is the point of equality? Ethics 109(2):287-337

Cohen GA (2008) Rescuing justice and equality. Harvard University Press, Cambridge

Cohen GA (2011) Luck and equality. In: Otsuka M (ed) on the currency of egalitarian justice and other essays in Political philosophy. Princeton University press, New Jersey, pp 116-123

Dworkin R (1981) What is equality? Part 2: equality of resources. Philos Public Aff 10(4):283-345

Elford G (2013) Equality of opportunity and other-affecting choice: why luck egalitarianism does not require brute luck equality. Ethical Theory Moral Pract 16(1):139-149

Lazenby H (2010) One kiss too many? Giving, luck egalitarianism and other-affecting choice. J Polit Philos 18(3):271-286

Miller D (2014) The incoherence of luck egalitarianism. In: Kaufman a (ed) distributive justice and access to advantage: G. A. Cohen's egalitarianism. Cambridge University press, Cambridge, pp 131-150.

Scheffler S (2003) What is egalitarianism? Philos Public Aff 31(1):5-39

Scheffler S (2005) Choice, circumstances and the value of equality. Politics, Philosophy and Economics 4(1):528

Segall S (2015) What's so egalitarian about luck egalitarianism. Ratio 28(3):349-368

Waldron J (2013) Political Political theory: an inaugural lecture. J Polit Philos 21(1):1-23

Wolff J (1998) Fairness, respect and the egalitarian ethos. Philos Public Aff 27(2):97-122

\footnotetext{
${ }^{17}$ For an influential egalitarian account of how the distance between unbridled inegalitarian choices and an appropriately responsibility-sensitive egalitarian distribution can be narrowed see G. A. Cohen's (2008) defence of an egalitarian ethos under which individuals refrain from choices with a tendency to create unfair inequality. ${ }^{18}$ For full disclosure, I believe there are reasons but that these are to do with the specific account of substantive responsibility that luck egalitarianism adopts and are therefore not reasons to reject responsibility-sensitive egalitarianism in general. It's also worth noting that whilst the Miller incoherence charge fails, the argument I have offered here does not establish that the kinds of gift inequalities I have discussed, which are in principle just under luck egalitarianism, in fact obtain in any widespread sense. I am grateful to an anonymous reviewer for emphasising this.
} 